\title{
Levator ani Avulsion Systematic Evidence Review (LASER)
}

\author{
Zdenek Rusavy $^{1}$, Lenka Paymova ${ }^{2}$, Michal Kozerovsky ${ }^{2}$, Adela Veverkova ${ }^{2}$, Vladimir \\ Kalis $^{2}$, Rasha Kamel ${ }^{3}$, and Khaled Ismail ${ }^{4}$ \\ ${ }^{1}$ Medical Faculty and University Hospital in Pilsen, Charles University in Prague \\ ${ }^{2}$ University Hospital and Charles University \\ ${ }^{3}$ Cairo University \\ ${ }^{4}$ Charles University Faculty of Medicine in Pilsen
}

November 12, 2020

\begin{abstract}
Background: There is variation in the reported incidence of levator avulsion (LA). Objective: Explore incidence of LA by mode of birth, imaging modality, timing of diagnosis and laterality of avulsion. Search strategy: We searched MEDLINE, EMBASE, CINAHL, AMED and MIDIRS with no language restriction from inception to April 2019. Study eligibility criteria: A study was included if LA was assessed by an imaging modality after the first vaginal birth or if only delivered by caesarean section. Case series and reports were not included. Data collection and analysis: RevMan v5.3 was used for the meta-analyses and SW SAS and STATISTICA packages for type and timing of imaging analyses. . Results: We included 37 primary non-randomized studies from 17 countries and involving 5594 women. Incidence of LA was 1\%, 15\%, 21\%, 38.5\% and 52\% following caesarean, spontaneous, vacuum, spatula and forceps births respectively, with no differences by imaging modality. OR of LA following spontaneous birth vs. caesarean was 10.69. While the OR for LA following vacuum and forceps compared to the spontaneous birth were 1.66 and 6.32 respectively. LA was more likely to occur on the right side following spontaneous birth $(\mathrm{p}=0.02)$ and unilaterally vs. bilaterally following spontaneous $(\mathrm{P}<.0001)$ and vacuum-assisted births $(\mathrm{P}=0.0103)$ only. Incidence was higher if assessment was performed in the first 4 weeks postpartum. Conclusions: Forceps significantly increases incidence and severity of LA. Ultrasound and MRI are comparable diagnostic tools but early postpartum imaging may lead to over diagnosis of LA.
\end{abstract}

\section{Hosted file}

LASER manuscript BJOG final.pdf available at https://authorea.com/users/375213/articles/ 492532-levator-ani-avulsion-systematic-evidence-review-laser

\section{Hosted file}

Table 1 LASER included studies final.pdf available at https://authorea.com/users/375213/ articles/492532-levator-ani-avulsion-systematic-evidence-review-laser

\section{Hosted file}

Table 2 LASER final.pdf available at https://authorea.com/users/375213/articles/492532levator-ani-avulsion-systematic-evidence-review-laser

\section{Hosted file}

LASER Figure 1 PRISMA Flow Diagram final.pdf available at https://authorea.com/users/375213/ articles/492532-levator-ani-avulsion-systematic-evidence-review-laser 


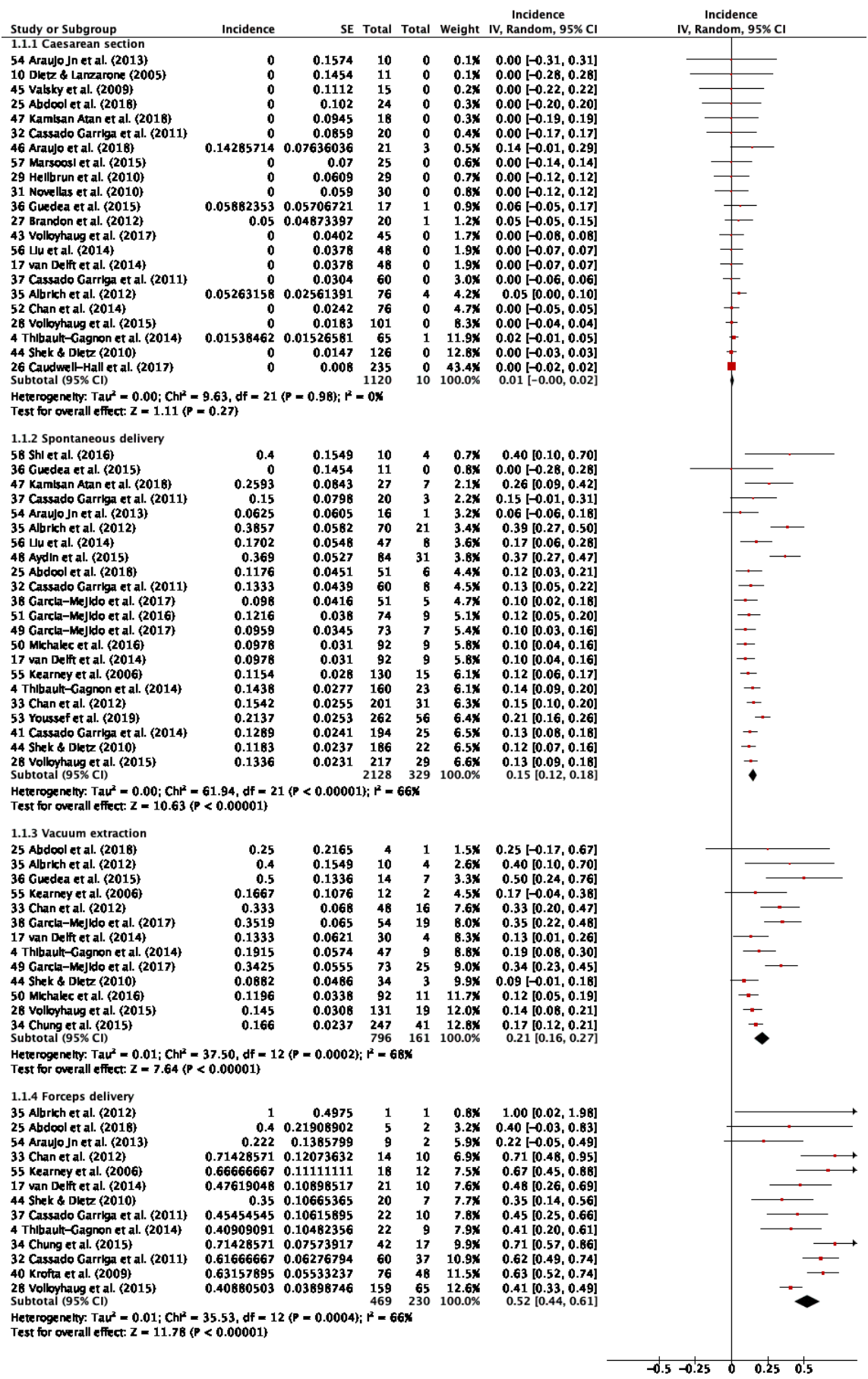


Odds Ratio

Events Total Events Total Weight M-H, Random, $95 \% \mathrm{CI}$

Odds Ratio

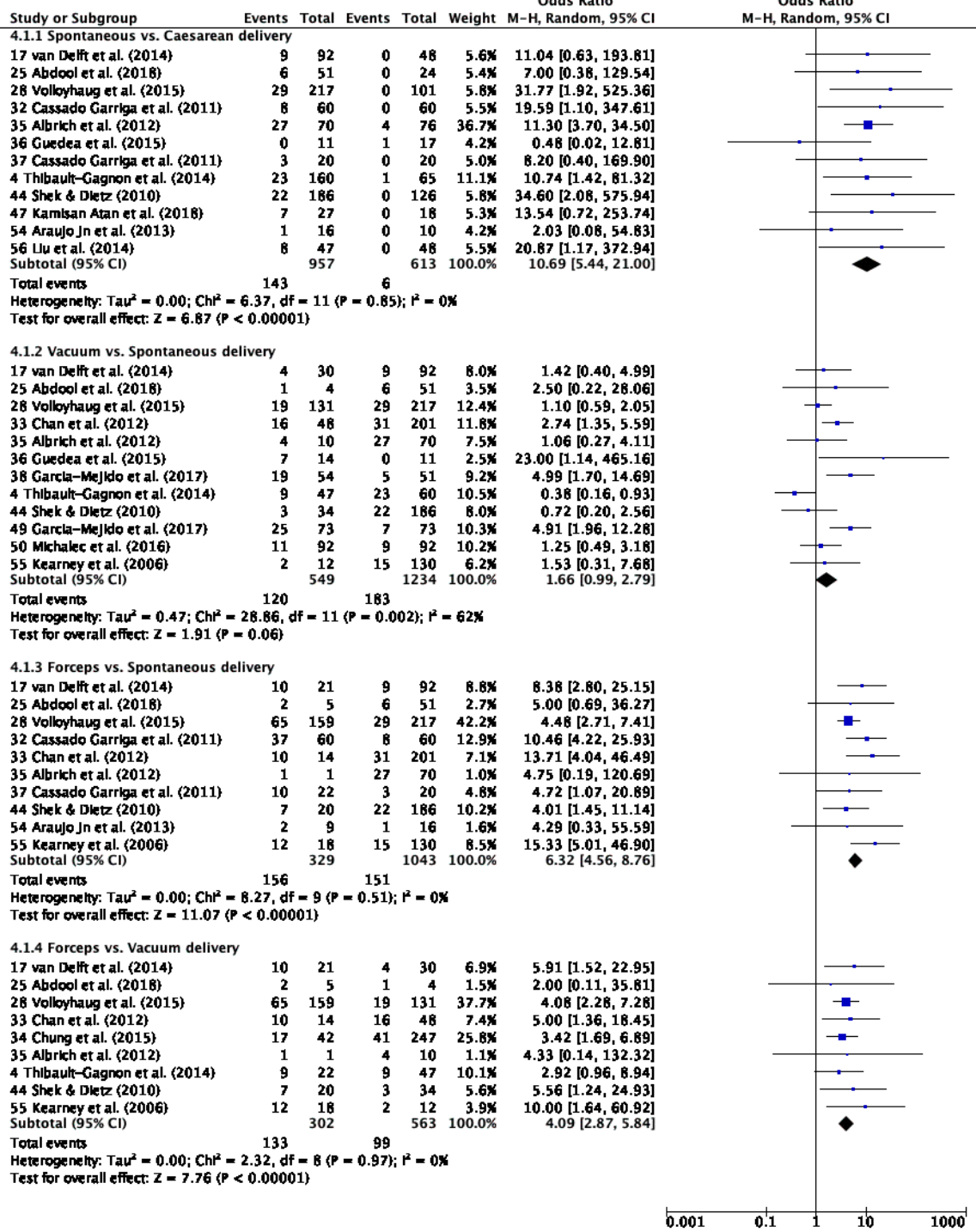

Test for subgroup differences: $\mathrm{Ch}^{2}=24.77, \mathrm{df}=3(\mathrm{P}<0.0001), \mathrm{I}^{2}=\mathrm{B7.9X}$ 


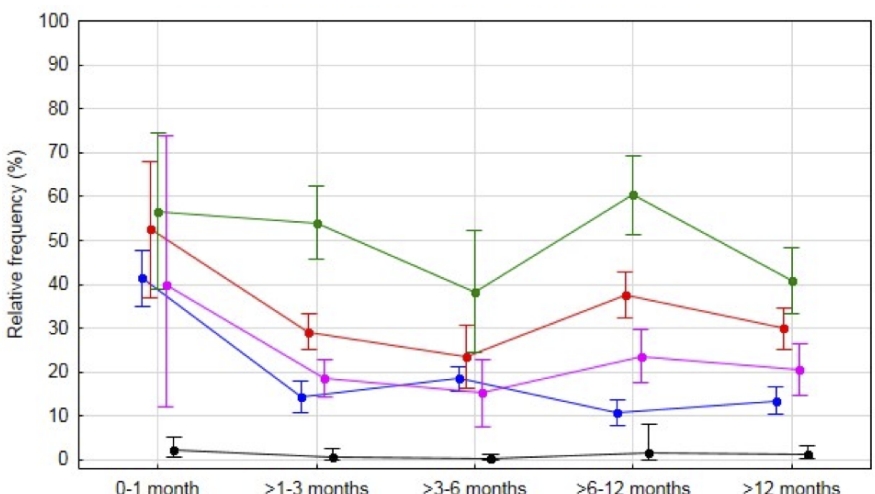

Spontaneous vaginal birth

- Operative vaginal delivery

Forceps

Cesarean section 